\title{
Experiencing resilience through the eyes of early career social workers
}

\begin{abstract}
Within the social work profession, resilience is integrated into educational programmes, professional development courses and frameworks. Such prevalence reflects the importance of resiliency for the profession. This may be the case in particular for those newer to the profession, where the challenges of managing the adversity synonymous with the social work role are still new, despite an increasing level of responsibility. This study focuses on early career social workers, an important but underexplored career stage within this occupation. The aim of which was to enhance understanding of how resilience is experienced by those who are in a unique transitional period in their careers; no longer students, whilst also not yet experienced social workers. The experiences of resilience for this group was explored through semi-structured interviews with fourteen social workers, all employed within Local Authorities in England. Through thematic analysis, three themes were identified: support, team dynamics, and maintaining professionalism. The findings offer important insights, which can inform and contribute to the supportive environments organisations can foster. As such, the practical implications of the research focus on fostering an environment of positivity, through more guided group supervision and the physical positioning of early career workers within office spaces.
\end{abstract}

Keywords: Social work, resilience, emotion, early careers 
Early career social workers' experiences of resilience

\section{Introduction}

The expected working life of a social worker in the United Kingdom (UK) is suggested to be only eight years (Curtis et al., 2010), with social work departments often facing high turnover rates. Within the Children and Family Social Work workforce, for example, turnover rates in 2017 were reported to be 15\% (Department for Education, 2018). The inevitable consequence of high turnover rates is an increase in caseloads for those who remain within the profession. For early career social workers, the increased pressure and expectation of higher caseloads with limited experience in the role could contribute to experiences of emotional burnout (Martin and Healy, 2010). Emotional exhaustion, a characteristic of emotional burnout, has been linked to resilience, with an increase in emotional exhaustion related to a lowered level of perceived resilience (McFadden et al., 2018). Given this increasing pressure, exploring the role of resilience is, therefore, fundamental to our knowledge surrounding the emotional well-being of social work employees. Importantly, in doing so, organisations can better equip themselves to help support resilience in the workplace.

The important role resilience plays within social work careers has amassed a significant amount of attention in the literature, with research focusing on, for example; how social work students are trained to be resilient (Grant and Kinman, 2012; Kinman and Grant, 2017; PalmaGarcia and Hombrados-Mendieta, 2014), what social workers understand resilience to be (Grant and Kinman, 2013) and how social workers engage with strategies to maintain a positive level of resilience in difficult working conditions (Adamson et al., 2014). While valuable insights can be garnered from this body of work, a gap in knowledge exists relating to our understanding of the experiences of resilience for those early on in their careers. Whilst qualitative research has reported the experiences of resilience from the perspective of social work students (Kinman and Grant, 2011), limited attention has been paid to those considered early career social workers. Early career social workers occupy a unique position within the 
Early career social workers' experiences of resilience

profession wherein they no longer identify as students, and do not benefit from the support of course supervisors, but are also several years away from being experienced social workers, with a battery of well-developed coping skills at their disposal. The ability to be resilient as an early career social worker may set the trajectory for their ongoing careers. In understanding the experiences of those who sit within this transition phase of their careers, it is anticipated that the results from this study can both contribute to existing literature on resilience and to inform organisations of effective ways to help support resiliency in early career social workers.

\section{Literature Review}

\section{Resilience}

Resilience is defined in a number of ways within the literature, often dependent on the approach or perspective taken, which has evolved over time (McFadden et al., 2018). Definitions often relate to two key components; the experience of adversity and positive adaptation in response to this (Adamson et al., 2014). People who display resiliency are able to tolerate difficult and stressful situations, as well as learn and gain strength from them (Fletcher and Sarkar, 2013). Resilience can act as a buffer for the negative effects of workrelated stress and may aid the development of positive adaptations and the ability to thrive even when facing such stressful events (Howard, 2008). In considering the emotional challenges that a social worker is faced with on a daily basis, it is clear to see why resilience comprises an essential skill within the Professional Capability Framework for Social Work in England (BASW, 2018). It is of paramount importance that those working in this context are confident and capable in their abilities to be emotionally resilient, in order to deal with such challenges. This seems even more pertinent for those newer to the field, with research showing that trainee social workers show high levels of work-related stress, possibly higher than qualified staff members (e.g. Barlow and Hall, 2007; Collins, 2008), while newly 
Early career social workers' experiences of resilience

qualified students in their first year of professional practice presented a decreasing sense of wellbeing during this time (Jack and Donnellan, 2010). Such findings are of concern, given that psychological negativity has the potential to impact those new to a career in social work very quickly (Kinman and Grant, 2017), highlighting the importance of understanding the experiences of resilience through the eyes of those in this unique transition phase of their careers.

There is a growing body of literature developing knowledge of the conditions that can help to nurture resilience in workers (Carson et al., 2011). For example; positive relationships with family, friends, colleagues and line managers (Bobek, 2002; McFadden, 2018), as well as the effective management of interactions that occur between personal and professional lives (Gu and Day, 2007). Other factors identified as important in building work-stress resilience include peer support, good communication skills, setting work and non-work boundaries, structured work routines, and self-reflection (Jensen et al., 2008). Research focusing on both social work students and experienced social workers identified intrapersonal (e.g. self-care and self-knowledge) and inter-personal (e.g. training and supervision) strategies as relevant (Grant and Kinman, 2013). Nurturing resilience then is not something that can be achieved by individual employees alone, the development of resilience requires a holistic approach. As Considine et al. (2015) suggest; focus is too often placed on personal qualities alone and responsibility placed on the individual to be able to cope with the demands of their work role. The suggestion here is that a more social and collegiate approach to understanding resilience should be taken, through social resilience; where focus lies in understanding the challenges faced by a group and the resources they require to manage these challenges.

\section{Emotion and resilience}


Early career social workers' experiences of resilience

What is evident from extant literature on the topic is that 'others' and emotion are key to our understanding of resiliency in social work. Being able to successfully manage emotion is fundamental for those working in social care (Howe, 2008) with links reported between emotion and self-reported resilience. (McFadden et al., 2018). The complexity of emotion experienced by those in social work is represented in the breadth of research exploring emotion within this context; such as, emotional intelligence, emotion management, positive emotion, and coping within the social work context (see, for example; Adamson et al., 2014; Kinman and Grant, 2011; Collins, 2008). Emotional intelligence (EI) has been defined by Goleman (1996, p. 34) as being able to "persist in the face of frustrations: to control impulse and delay gratification; to regulate one's moods and keep stress from swamping the ability to think; to empathise and to hope". Within the social work context, research has found EI to be a fundamental protective quality against work-related stress and a key predictor of resilience within social work students (Kinman and Grant, 2011; Grant and Kinman, 2012). Findings from Kinman and Grant's (2011) study suggest the ability to reflect, and the ability to moderate the extent to which empathy is shown to service users, are effective mechanisms of self-protection evidenced in those who are more effectively resilient.

Mechanisms of self-protection can be found in various other forms throughout the literature; Collins (2007), for example, highlighted the role of positive emotions and coping for those who work in inherently stressful situations, where the most prevalent emotions are negative in valence. Utilising positive emotions during a difficult emotional experience, to manage the negativity, is in line with the suggestion that being emotionally intelligent is an important underlying component of being a resilient social worker. While there is evidence to suggest that positivity is a useful approach to being resilient, there is also evidence to suggest that, in practice, social work students may not always veer automatically towards the positive. Rajan-Rankin (2014), for example, found that the students interviewed were often 
Early career social workers' experiences of resilience

pessimistic in their outlook, rather than hopeful or optimistic. This finding is troublesome when considering evidence that negative emotional experiences are linked to low levels of perceived resilience (McFadden et al, 2018). Interestingly, Rajan-Rankin (2014) found that these social work students maintained a sense of professional self-identity through containing their emotion at work, whilst also acknowledging that awareness and acceptance of one's own emotions was crucial in developing their own resilience - and in doing so, being a professional social worker. Extant literature, therefore, highlights the complexities and nuances of managing emotion in relation to one's own resiliency.

\section{Support and resilience}

Much of the literature investigating resilience in social workers refers to the role of others, through the provision of social or organisational support. In a systematic review of the literature, focusing on resilience and burnout in child protection social workers, McFadden et al. $(2015 ; 2018)$ identify peer and management support as contributing to retention, while buffering against burnout and turnover. Supportive work environments have been found to reduce the likelihood of secondary traumatic stress and compassion fatigue; the emotional and behavioural responses experienced by those who are in regular contact with individuals that have experienced personal trauma (Slattery and Goodman, 2009; Kapoulitsas and Corcoran, 2015). The findings from Kapoulitsas and Corcoran, however, also suggest that supervision is not always regarded as being a positive experience. Although crucial to their working environment, some participants identified potentially harmful impacts to their resilience of poor supervisor experiences. While other research has suggested that the absence of a positive relationship with a line manager contributed to decisions to leave an organisation (McFadden, 2018), compounding the importance of effective supervisory support. Pack (2015) suggested that effective supervisory support is signified by supervisees 
Early career social workers' experiences of resilience

feeling safe with their supervisor and also perceiving a sense of ownership over the content and structure of their supervisory sessions.

In addition to formal supervisory support fostering the development of social work professionals (McFadden 2018; Pack, 2015), the significance of informal workplace support cannot be underestimated. Workplace learning occurs through a variety of networks, both professional and personal (Berg and Cheung, 2008), with evidence suggesting that the experiences of those new to the profession are shaped by their colleagues (Moriarty et al., 2011). Alternative methods of supervision, such as peer or group supervision, and forming communities to engage in discussion about work, have long been used by those in the social work profession (Noble and Irwin, 2009). Informal support, alongside formal support processes, is necessary in nurturing workers who are able to manage the daily difficulties they face at work through developing both their knowledge and their skills set; effectively, developing resilient employees (Carson et al., 2011).

\section{Current Study}

Much of the literature investigating social worker resilience within a specific career stage has focused on social work students, or experienced social workers (e.g. Grant and Kinman, 2013). There is little research investigating social workers who are transitioning from recently graduated to an experienced social worker. The evidence suggesting there is the potential for psychological negativity to quickly impact upon those new to a career in social work (Kinman and Grant, 2017) is of concern, given that evidence has suggested newly qualified social workers experience a decreasing sense of wellbeing over their first year of professional practice (Jack and Donnelan, 2010). The experiences of resilience for those occupying this unique phase of their career development may contain complexities and nuances that are yet to be revealed. As such, the aim of this study is to investigate how early 
Early career social workers' experiences of resilience

career social workers experience resilience, with a specific focus on their emotional experiences. The focus of this study makes an important contribution to extant literature; it offers an insight into the ways in which the working environment is negotiated, and resilience training is put into practice, by those in the early stages of their professional career.

\section{Method}

Interviews with UK social workers were conducted. Recruitment of participants was through a snowball sampling approach; existing contacts of the researchers contacted potential participants with an overview of the research study. Those interested in being a participant contacted the researchers directly to receive the full information sheet; this detailed the extent of their participation in the research, ensuring they were fully informed before consenting to participate. The research received ethical approval from the University Ethics Committee of the University of Winchester.

\section{Participants}

Fourteen UK social workers took part in the interviews, all of whom were female and worked within Local Authorities in South East England. Participants were all considered early career social workers, having been working in the profession for less than three years. Whilst the definition of 'early career' varies across the literature, the cut-off point of three years was made on the basis of the phases of professional development outlined by Ronnestad and Skovolt (2003), within the counsellor/therapist context. This paper suggests that the novice professional phase lasts for the first few years following graduation, moving on to the experienced professional phase after having practiced for a number of years and in different settings. Participants were employed in a variety of social work roles from both child and adult services.

\section{Procedure}


Early career social workers' experiences of resilience

Semi-structured interviews were carried out by one member of the research team. Interviews lasted approximately one hour and were primarily conducted face-to-face (at the participants' place of work, or the researcher's office). Two interviews were conducted via telephone, for the convenience of the participants. Telephone interviews have previously been evidenced as a valuable medium for qualitative data collection (Cachia and Millward, 2011). Participation in the interviews was voluntary, with a $£ 20$ voucher offered to acknowledge our appreciation of their time. Participants consented to interviews being audio recorded, to allow for transcription, and were aware they could withdraw at any time.

To encourage discussion of resilience in a way that was most relevant and important to the participants, a semi-structured interview guide was used. The interview guide was divided into three main sections, focusing on: participants' experience of emotion (for example; 'How would you describe your emotional experiences at work?'), resilience (for example; 'To what extent do you feel equipped to deal with your emotional experiences at work?'), and finally, how resilience is put into practice (for example; 'To what extent do you feel confident in applying the techniques/strategies you have learnt?').

\section{Analysis}

Analysis of the data was through a contextualist thematic analysis and followed the phases outlined by Braun and Clarke (2006). Transcribed interviews were read by all members of the research team, to ensure complete familiarity. To gain agreement of coding during the analytic process, a proportion of transcripts (20 percent) were independently blind coded by the research team and agreement was reached before analysis of the full data set commenced. Codes of interest to the aims of the study were identified by researchers across the entire data set; to ensure all data was considered in relation to the final thematic understanding of the data set, both high and low frequency codes were considered. The revision and reviewing of 
Early career social workers' experiences of resilience

codes between the research team occurred throughout the entire analytic process and there was agreement across all researchers of the final thematic scheme.

\section{Findings}

Three themes were identified across the data set, including: support, team dynamics, and maintaining professionalism. Taken together, these themes provide an insight into the experiences of resilience, as seen through the eyes of early career social workers.

\section{Support}

Participants described how the development of resilience was enhanced through emotional support, which came from two primary sources; supervisors and peers.

\section{Supervisory role}

In line with existing research (McFadden 2018; Pack, 2015), the majority of social workers identified supervisors and regular supervision as a fundamental source of emotional support and 'vital for the role' (P2). When asked what supervision meant to them, one participant said: 'I'd say that's key in being able to sort of manage your own well-being' (P11). For several participants, supervision was described in a very positive way, allowing them to take this necessary time to focus on their emotional well-being: 'my manager says to me, right, this is your personal supervision and we talk about emotions we do some critical reflection' (P9).

When those who described a positive supervisory experience were asked if they felt their experiences were reflective of other early career social workers, they did not perceive their situation to be one of normal expected practice, but that they were 'lucky' to find themselves in such a positive situation: “I'm lucky I know I'm lucky umm I have colleagues...that don't get that good level of personal supervision and I know that I am lucky." (P9). Regular supervision, with time and focus directed at their emotional well-being 
Early career social workers' experiences of resilience

was a rarity for some participants. One participant stated that supervision sessions are a discussion of their current cases, as there is not 'room for the emotional side of things' (P8). Those participants who perceived their supervisory support to be less often or less positive than expected, often mentioned high levels of sick leave across their departments and time pressures on themselves and their managers. One participant described a disregard for protected supervisory time, '...you'll be in supervision and someone will knock on the door and then she'll just leave but that's meant to be protected time' (P7). As suggested by Kapoulitsas and Corcoran (2015), such negative experiences of supervisory support may be having detrimental impacts on these social workers.

Whether participants felt their own supervision was in line with their expectations or not, it was evident that positive experiences with a supervisor were essential to both the confidence and resilience of early career social workers:

...in this team I feel happy and secure and enthusiastic about the work.

I haven't felt stressed yet because it's well managed and my manager is always there but in my last team I felt stressed and anxious and worried, concerned and not very resilient. (P7)

While participants acknowledged that there was also a responsibility of all staff members to maintain their own resiliency, as one participant stated: 'a lot is to be said for management and support and quality of supervision' (P9).

\section{Peer support}

Participants frequently discussed the role their peers played in supporting the management of their emotion and development of resilience. The role of their peers was primarily in being there to talk to about concerns or emotional experiences, '...we all sit and talk about our worries and it makes me feel better knowing they feel the same way...so it's sort of 
Early career social workers' experiences of resilience

reassuring it's not just me.' (P8). Support within the team was considered by many as crucial for both the immediate relief and reassurance it bought, but also as an important strategy to prevent any longer-term negative impacts on the individual and the wider team: 'we've got low sickness levels in our team because I think we do support each other well' (P5). For this participant there was, again, the sense that being in a supportive and positive team environment was down to luck, rather than something to be expected, 'I think we're lucky with our team.' (P5).

Group supervision was identified by some participants as a positive experience and a way to share strategies to remain resilient; when asked if resilience forms a part of their discussions, one participant stated that 'Yes, we discuss it quite a lot in group supervision about what we sort of do to manage our stress' (P6). For others, however, group supervision with all colleagues was often referred to as evoking and perpetuating negativity. For one participant in particular, group supervision offered only negative experiences and no suggestions of how to increase resilience against these experiences:

Some weeks it's just people moaning about stuff and that's really just soul destroying ... we never talk about sort of how to manage emotions or stress or anything like that it's just literally people moaning... (P8)

Creating communities of coping, by seeking support from colleagues when faced with persistent negativity, has been identified as a crucial coping mechanism when working within a service industry (Korczynski, 2003). For this participant, however, merely talking about the negative experiences is not sufficient, they desire discussion of practical support within this context.

Other early career social workers offer an additional level of group support, where emotional experiences and techniques are shared in an informal way. The focus on positivity and positive emotion was frequently mentioned as an important element of this support: 'We 
Early career social workers' experiences of resilience

sort of have like a WhatsApp group to do check ins throughout the day ... so we've been trying to keep it more on the positive side' (P11). Focusing on positives and encouraging positive reappraisal of situations has been identified as a key element of coping (Folkman and Moskowitz, 2000) and is something that early career social workers are engaging with on an informal basis.

\section{Team dynamics}

The dynamics of organisational teams were identified by participants as playing a role in the ways they experienced emotion and the extent they were able to be resilient to negative experiences. This was in relation to two aspects of their team dynamics; the position they held within the organisation and the physical environment within which the teams worked.

\section{Position within the organisation}

Participants were acutely aware of their position and made a clear distinction between themselves and the more experienced social workers. Primarily this distinction was in relation to the level of support they received, for instance, one participant did not perceive experienced social workers to get any emotional support:

I don't think they get that support ...we can discuss emotion...I see other people having really really difficult things to deal with and it's just it's almost as if nothing is there for them not in the way that I would hope there is. (P12) In fact, there was a clear perception that once they were no longer considered early career social workers, their experiences would change dramatically. One participant described being called 'lucky' by more experienced social workers for having regular supervision and also feeling fearful about the future: 'it's quite scary actually...in a year or so I might be in that 
Early career social workers' experiences of resilience

position where I don't feel as supported and I do feel more overwhelmed and stressed and that's quite scary.' (P9).

It also appeared that social workers early on in their careers perceived themselves as more emotional than those more experienced workers, partly because, 'people almost get harder the longer they have been doing the job' (P3), but also due to the difficulty of the role itself, 'when you are newly qualified they are all new experiences for you. Nobody prepares you for things like that you know.' (P3).

\section{Physical environment}

The distinction between early career and experienced social workers was exemplified for some through a physical segregation from their more experienced colleagues. This segregation had two main functions; protection from negativity and enforcement of a strong group identity. One participant described agency workers moving over to 'our corner' because: 'it must be a nicer environment...the other side can get quite negative sometimes...it feels a bit safer' (P11). This participant valued the early career group identity that had been created; 'I mean it's quite nice that we've got our own identity', whilst also acknowledging that an increase in experience will be signified by them moving over to 'the

other side' (P11). For these participants, the use of physical space was acting as an identity cue, which can reinforce a salient organisational identity (Ashforth et al., 2008). For the majority of participants, there was a clear desire to preserve their experiences of positive emotion, compared to the more negative emotion they perceived was experienced by their more experienced colleagues.

\section{Maintaining professionalism}


Early career social workers' experiences of resilience

Being resilient for these social workers involved a professional approach to their own and others' emotions, which was done in two ways; through maintaining a level of emotional distance between themselves and both colleagues and service users, and also through training to be emotionally professional.

\section{Emotional distance}

For several of the participants, the effectiveness of their job relies on them being in control, emotionally, as one participant explained: 'If I wasn't emotionally resilient I wouldn't be able to support the families in the way that I do' (P6). It was also important for participants to protect themselves from their colleagues' emotional distress, while also being supportive: 'you can be there to support somebody but don't let their feelings and their worries and their stresses burden you as well' (P2). For many of the participants, limiting or preventing emotional transference from others, be it service users or colleagues, was seen as a fundamental skill to maintain one's own emotional resilience. Keeping a level of 'professional' emotional distance was one way of ensuring they showed empathetic concern, which can have beneficial effects on resiliency, rather than empathetic distress, which can have deleterious effects (Kinman and Grant, 2011).

\section{Training to be emotionally professional}

All participants expressed an acknowledgement that their chosen career path was not going to be an easy one and that experiencing stress and negative emotions was inevitable, 'If you're not stressed at work you know you're not really a social worker I don't think.' (P9). However, the experiences of resilience training whilst early on in their careers was seen, by the majority of participants, to be beneficial in helping them manage this inevitable stress. 
Early career social workers' experiences of resilience

When asked about the training of resilience on university courses, several of the participants suggested the need for more skills-based training; offering them more practical advice for dealing with their emotional experiences, 'I think I wanted practical stuff, stuff that I could actually use and implement and that would help but we didn't really get that from it.' (P8). There was also the suggestion that the amount of training, particularly in relation to practical techniques, could be increased for those early on in their careers: 'We did have a skills day that was around emotional resilience...things like that need to be done every year or have more than one session on it' (P2).

For some participants, the development of their resilience and knowledge of techniques to employ came from the training and courses completed as part of their Assessed and Supported Year of Employment (ASYE). The ASYE is designed to support and develop the skills that Newly Qualified Social Workers (NQSW) will use in practice. The training received was regarded in a positive light by the majority of participants, '...we've had a three-day resilience course and the first day that we did was all about us and it was fantastic' (P7). However, there remained an expectation that, as a social worker, you just have the ability to deal with stress and negativity: "I think it's just expected that you carry on get on with it" (P8).

\section{Discussion}

The primary aim of this research was to examine how early career social workers experience resilience. Early career social workers sit in an interesting space between students and more experienced social workers - they are still close, in time, to their experiences of being a student and are new to many work-related experiences, however, they are also qualified and given increasing levels of responsibility. The themes identified show some similarities to the experiences of social workers at different levels of their careers, however, they also offered 
Early career social workers' experiences of resilience

some novel insights into the ways early career social workers, within Local Authorities in England, negotiate their work environments to manage their ability to be resilient.

The findings highlighted that those early on in their careers perceive support from others, both supervisors and peers, as fundamental in the maintenance and development of their resilience. In particular, peers were used as an important gauge for validating their own emotional experiences. There was a desire to protect the secure bond they had developed with their peers, through physical segregation from their more experienced colleagues. Despite feeling a close and important bond to their peers, maintaining a level of emotional distance from colleagues was also of paramount importance to ensure a level of professionalism in the management of their emotion.

As has been found in research on social workers at other stages of their career, early career social workers perceived that their ability to be resilient was enhanced by the support of others, both in a formal and informal sense (Grant and Kinman, 2013; McFadden, 2018). Within the formal context of supervision, the social workers in this study expressed a sense of being 'lucky' if they felt their supervision experience was positive and there was focus given to discussing emotion within these sessions. Although such supervisory experiences would be considered an expectation for social workers, particularly those early on in their careers, the meeting of this expectation was experienced in an extremely positive way, as more of an exceeded, than a met, expectation. Exceeded expectations in relation to support have previously been linked to an increase in employee satisfaction (Irving and Montes, 2009). The realities of working in such a time pressured environment may be contributing here to the supervisory support of emotion being experienced in a more positive way than would have been anticipated. 
Early career social workers' experiences of resilience

Such perceptions of luck also extended to the experience of having a positive team environment, with great emphasis placed on the importance of peers. Interestingly for this group of social workers, peers acted as a barometer for their own emotional experiences. They sought reassurance from peers that their emotional experiences were not unique, but inline with others in their position. Social comparison; when an individual compares their own perceptions and opinions with those around them, is particularly active when the experience is either confusing or there is a lack of any real objective standards (Festinger, 1954; Kulik and Mahler, 2000). For those early on in their careers, where the emotional experiences may be new, or complex, such social comparison is acting as an important guide in how emotional experiences are made sense of and managed.

Physical space (relating here to sitting in a specific area of a large office) was utilised by these early career social workers to provide a clear segregation from their more experienced colleagues. The reasons behind which held a dual function; firstly, as a form of physical protection against the perceived negativity emanating from their colleagues, whilst secondly acting to create an ever more collegiate group with their peers. Emotional contagion; emotionally converging with another person (Hatfield et al., 1994), can lead to one feeling some level of the emotion being mimicked, albeit often at a reduced intensity (Wild et al., 2003). The transmitting of emotion within a group requires direct, face-to-face, contact (Barside, 2002), so the physical separation of early career workers from their experienced colleagues may indeed be acting to protect them from experiencing unnecessary negative emotion. It is evident from the findings that early career social workers identify closely with their peers and such physical positioning of themselves within the workspace is helping to further enhance this organisational identity (Ashforth et al., 2008). It is also possible that grouping themselves together in this way is contributing to their sense of social resilience; where a collective approach to adversity is taken (Considine et al., 2015). Focus is 
Early career social workers' experiences of resilience

placed on the challenge's groups are faced with and the resources they need to allow them to cope. Feeling physically close to their peers contributes to both the emotional experiences and sense of resilience within these early career social workers. Although it may prove difficult for some workplaces, on a practical level, physical segregation of early career employees within the workspace could offer a useful strategy for organisations to implement.

\section{Limitations}

The sample used in this study could be considered a limitation; fourteen women, primarily white British, all of which worked for Local Authorities in the South East of England, participated in the research. The sample consisting only of women reflects the underrepresentation of men pursuing social work as a career. Collecting data from early career researchers within Local Authorities in a specific region of the UK has provided an understanding of experiences from within a very specific context. Future research could extend understanding of these experiences through the exploration of early career social workers in different contexts. One possibility would be to investigate other regions of the UK, which may differ in the extent to which they are considered urban/rural and in their cultural diversity. Research that offers support to this as a fruitful area of investigation comes from the youth resilience literature, where it is suggested that there are cultural complexities in how one experiences resilience (Ungar, 2008). A further possibility would be to focus instead on private organisations. The organisational context and pressures across public and private sector organisations, for example, differs and it is likely, therefore, that experiences of resilience would also differ. In a similar vein; experiences of resilience may also differ across specific roles within social work. The current study recruited participants from across a range of roles, both within child and adult services. Future research may wish to explore experiences of resilience in early career social workers within specific role contexts. As is the case with qualitative research, data saturation was a significant consideration in the 
Early career social workers' experiences of resilience

recruitment of participants; after collecting data from fourteen participants, data saturation was achieved.

\section{Conclusion and Practical Implications}

This study examined experiences of resilience through the eyes of early career social workers; a group who sit within a unique transition phase of their social work careers. The insights garnered from this research contribute to the literature on resilience in social work, offering valuable insights into the ways this group manage their ability to be resilient and how their working environments are negotiated in order to support this. Acknowledging the complexities inherent in supporting the resilience of social work employees, the practical suggestions proposed here are intended to complement the wider support structures already in place within organisations, with a specific focus on the support that can be offered to early career employees.

Firstly, this research would suggest that qualified social workers and/or team leaders focus on supporting a more positive environment for early career social workers to experience their emotion. Considering the physical positioning of early career employees within their office space is one practical way of doing this. The current study suggests that a clear group identity within the early career employees can help to encourage positivity within this group. Senior members of the team could manage the physical space by clearly allocating a specific area for early career social workers to sit together; this could help to support their collegiate group identity and go some way towards safeguarding them from the negative emotional experiences of others.

Secondly, the findings from this research suggest that the purpose and internal management of group supervision should be carefully considered by more senior members of staff. Participants in this study discussed positive experiences of group supervision as 
Early career social workers' experiences of resilience

providing opportunities to share emotional experiences and discuss the practical strategies used to manage them. Communities of coping (Korczynski, 2003) is likely to be an essential mechanism feeding into the resilience of early career social workers, meaning group supervision sessions need to be carefully managed to prevent them from becoming merely an opportunity to offload negativity. Experienced social workers should be mindful of the possibility for group supervision to positively contribute to resilience. Harnessing a more positive and practical focus within these sessions may be an important and beneficial contribution to the resilience of their early career employees.

\section{References}

Adamson, C., Beddoe, L. and Davys, A. (2014) 'Building resilient practitioners: Definitions and practitioner understandings', British Journal of Social Work, 44, pp. 522-541.

Ashforth, B.E., Harrison, S.H. and Corley, K.G. (2008) 'Identification in organisations: An examination of four fundamental questions', Journal of Management, 34(3), pp. 325374.

Barlow, C. and Hall, B.L. (2007) 'What about feelings? A study of emotions and tensions in social work field education', Social Work Field Education, 26(4), pp. 1-15.

Barside, S.G. (2002) 'The ripple effect: emotional contagion and its influence on group behavior', Administrative Science Quarterly, 47(4), pp. 644-675.

BASW (2018) 'Professional Capabilities Framework for Social Work in England', available online at https://www.basw.co.uk/professional-development/professional-capabilitiesframework-pcf/.

Braun, V. and Clarke, V. (2006) 'Using thematic analysis in psychology', Qualitative Research in Psychology, 3(2), pp. 77-101. 
Early career social workers' experiences of resilience

Berg, S.A. and Cheung, S.Y. (2008) 'Factors that influence informal learning in the workplace', Journal of Workplace Learning, 20(4), pp. 229-244.

Bobek, B.L. (2002) 'Teacher resiliency: The key to longevity', The Clearing House, 75(4), pp. 202-205.

Carson, E., King, A., and Papatraianou, L.H. (2011) 'Resilience among social workers: The role of informal learning in the workplace', Practice, 23(5), pp. 267-278.

Collins, S. (2008) 'Statutory social workers: Stress, job satisfaction, coping, social support and individual differences', British Journal of Social Work, 38, pp. 1173-93.

Considine, T., Hollingdale, P. and Neville, R. (2015) 'Social work, pastoral care and resilience', Pastoral Care in education, 33(4), pp. 214-219.

Curtis, L., Moriarty, J. and Netter, A. (2010) 'The expected working life of a social worker', British Journal of Social Work, 40(5), pp. 1628-1643.

Department for Education. (2018) Experimental statistics: Children and family social work workforce in England, year ending 30 September 2017, Retrieved from https://assets.publishing.service.gov.uk/government/uploads/system/uploads/attachme nt_data/file/681546/SFR09-2018_Main_Text.pdf

Festinger, L. (1954) 'A theory of social comparison processes', Human Relations, 7(2), pp. $117-140$.

Fletcher, D. and Sarkar, M. (2013) 'Psychological Resilience: A review and critique of definitions, concepts and theory', European Psychologist, 18(1), pp. 12-23.

Folkman, S. and Moskowitz, J. (2000) 'Positive affect and the other side of coping', American Psychologist, 55(6), pp. 647-654.

Goleman, D. (1996) Emotional Intelligence, London, Bloomsbury.

Grant, L. and Kinman, G. (2012) 'Enhancing wellbeing in social work students: Building resilience in the next generation', Social Work Education, 31(5), pp. 605-621. 
Early career social workers' experiences of resilience

Grant L. and Kinman, G. (2013) ‘'Bouncing back?’ Personal representations of resilience of student and experienced social workers', Practice, 25(5), pp. 349-366.

Gu, Q. and Day, C. (2007). 'Teachers resilience: A necessary condition for effectiveness', Teaching and Teacher Education, 23(8), pp. 1302-1316.

Hatfield, E., Cacioppo, J. and Rapson, R.L. (1994) Emotional contagion, New York, Cambridge University Press

Howard, F. (2008) 'Managing stress or enhancing well-being? Positive psychology's contributions to clinical supervision', Australian Psychologist, 43(2), pp. 105-13.

Howe, D. (2008) The Emotionally Intelligent Social Worker, London, Palgrave McMillan.

Irving, G. and Montes, S.D. (2009) 'Met expectations: The effects of expected and delivered inducements on employee satisfaction', Journal of Occupational and Organizational Psychology, 82(2), pp. 431-451.

Jack, G. and Donnellan, H. (2010) 'Recognising the person within the developing professional: Tracking the early careers of newly qualified child care social workers in three Local Authorities in England', Social Work Education, 29(3), pp. 305-318.

Jensen, P.M., Trollope-Kumar, K., Waters, H. and Everson, J. (2008) 'Building physician resilience', Canadian Family Physician, 54(5), pp. 722-9.

Kapoulitsas, M. and Corcoran, T. (2015) 'Compassion fatigue and resilience: A qualitative analysis of social work practice', Qualitative Social Work, 14(1), pp. 86-101.

Kinman, G. and Grant, L. (2011) 'Exploring stress resilience in trainee social workers: The role of emotional and social competencies', British Journal of Social Work, 41, pp. 261275.

Kinman, G. and Grant, L. (2017) 'Building resilience in early-career social workers: Evaluating a multi-modal intervention', British Journal of Social Work, 47(7), pp. 1979-1988. 
Early career social workers' experiences of resilience

Klarreich, S. (1998) Handbook of Organizational Health Psychology: Programs to Make the Workplace Healthier, Madison, CT Psychosocial Press.

Korczynski, M. (2003) 'Communities of coping: Collective emotional labour in service work', Organization, 10(1), pp. 55-79.

Kulik, J.A. and Mahler, H.I.M. (2000) 'Social comparison, affiliation and emotional contagion under threat', in Slus, J. and Wheeler, L. (eds), Handbook of Social Comparison: Theory and Research, New York, Springer Science and Business Media.

McFadden, P. (2018) 'Two sides of one coin? Relationships build resilience or contribute to burnout in child protection social work: Shared perspectives from leavers and stayers in Northern Ireland', International Social Work, pp. 1-13. doi:10.1177/0020872818788393

McFadden, P., Campbell, A. and Taylor, B. (2015) 'Resilience and burnout in child protection social work: Individual and organisational themes from a systematic literature review', British Journal of Social Work, 45(5), pp. 1546-1563.

McFadden, P., Mallett, J., Campbell, A. and Taylor, B. (2018) 'Explaining self-reported resilience in child-protection social work: The role of organisational factors, demographic information and job characteristics', British Journal of Social Work, pp. 1-19, doi: 10.1093/bjsw/bcy015

Moriarty, J., Manthorpe, J., Stevens, M. and Hussein, S. (2011) 'Making the transition: Comparing research on newly qualified social workers with other professions', British Journal of Social Work, 41(7), pp. 1340-1356.

Noble, C. and Irwin, J. (2009) 'Social work supervision: An exploration of the current challenges in a rapidly changing social, economic and political environment', Journal of Social Work, 9(3), pp. 345-358. 
Early career social workers' experiences of resilience

Pack, M. (2015) 'UUnsticking the stuckness': A qualitative study of the clinical supervisory needs of early-career health social workers', British Journal of Social Work, 45(6), pp. $1821-1836$

Palma-Garcia, M. de las O. and Hombrados-Mendieta, I. (2014) 'The development of resilience in social work students and professionals', Journal of Social Work, 14(4), pp. 380-397.

Ranjan-Rankin, S. (2014) 'Self-identity, embodiment and the development of emotional resilience', British Journal of Social Work, 44(8), pp. 2426-2442.

Ronnestad, M.H. and Skovholt, T.M. (2003) 'The journey of the counsellor and therapist: Research findings and perspectives on professional development', Journal of Career Development, 30(1), pp. 5-44.

Slattery, S.M. and Goodman, L.A. (2009) 'Secondary traumatic stress among domestic violence advocates: Workplace risk and protective factors', Violence Against Women, 15(11), pp. 1358-1379.

Ungar, M. (2008) 'Resilience across cultures', The British Journal of Social Work, 38(2), pp. 218-235.

Wild, B., Erb, M., Eyb, M., Bartels, M and Grodd, W. (2003). Why are smiles contagious? An fMRI study of the interaction between perception of facial affect and facial movements. Psychiatry Research: Neuroimaging, 123(1), pp. 17-36. 